\title{
DETERMINING QUALITIES OF PHOTOGRAMMETRIC MODELS FOR THE USE OF MONITORING MOVEMENTS IN STONE CANDIS IN CENTRAL JAVA
}

\author{
D. GRANDITS ${ }^{1}$, L. STAMPFER ${ }^{2}$, E. KODŽOMAN ${ }^{2}$ AND U. HERBIG ${ }^{2}$ \\ ${ }^{1}$ TU Wien, Inst. of History of Art, Building Archaeology and Restoration, Research Unit of \\ Monument Preservation (doris.grandits@tuwien.ac.at) \\ denkmalpflege.tuwien.ac.at \\ ${ }^{2}$ TU Wien, Inst. of History of Art, Building Archaeology and Restoration, Research Unit Building \\ History and Building Archaeology (lukas.stampfer, eva.kodzoman, herbig@tuwien.ac.at) \\ baugeschichte.tuwien.ac.at
}

Keywords: Photogrammetry, Recording, TLS, Monitoring, hybrid methods in photogrammetry, Indonesian Temples

\begin{abstract}
The Candis (temples) of Java represent sophisticated ancient building heritage and are key features for Javanese people to identify with their own culture. Candis occupy a significant position in the cultural history of Southeast Asia and rank among the most outstanding examples of Buddhist and Hindu architecture. Well-known Candis such as Borobudur or Prambanan are also top-ranked tourist destinations.

This ancient heritage is threatened by Indonesia's geographical location within the Pacific Ring of Fire, a tectonic subduction zone prone to environmental catastrophes such as earthquakes, volcanic eruptions and the resulting tsunamis. Previous work presented a monitoring workflow for analysing variations in the geometry of these temples to gain an understanding of structural changes produced by seismic events. As part of that workflow, we proposed a combined laser scanning and UAV-supported image match point cloud model which can be compared to a photogrammetric data set in order to provide a quick, inexpensive, and easily accessible monitoring technique. While methodology has already proved useful, some aspects still need to be refined. Also, further understanding about the structural composition of the objects being examined and what changes of geometry can be expected within the analysis after earthquakes needs to be collected.

An analysis is presented of changes that have happened within the structure over a period of several years and numerous seismic events to facilitate an understanding of geometric changes that can occur. Furthermore, this re-evaluation by laser scanning will be compared to a set of image-match models to investigate factors that have an impact on the reliability and accuracy of such models. Manuals drafted by the project team and introduced in previous work explain how to capture image data to be processed into photogrammetric models. Amendments and revisions will be made to these manuals based on new data and experiences collected during the ongoing Candi Sari case study presented in this paper.
\end{abstract}




\section{INTRODUCTION}

\subsection{Indonesia and its cultural heritage}

Indonesia is the largest island state in the world, comprising more than 17,000 islands, and inhabited by about 240 million people. The island of Java, on which the capital Jakarta is located, is Indonesia's most densely-populated island, where more than $60 \%$ of all its inhabitants live. Indonesian culture is as diverse as the archipelago itself. In addition to its geographical characteristics, reasons for the diversity and richness of Indonesian culture are the variety of traditions and different religions that have always existed side by side. ${ }^{1}$ Numerous temples and temple ruins also bear witness to this cultural wealth and to the island's history. These temples, known as Candis, occupy an eminent position in the cultural history of Southeast Asia and are among the most outstanding examples of Buddhist and Hindu architecture.

\subsection{The Candis of Java}

The term Candi is used to describe all Buddhist and Hindu temples in Indonesia. The highest concentration of temples is in the centre of Java. In the administrative districts of Yogyakarta Special Region and Central Java, there are some 280 of these monumental relics. Complexes on the Dieng plateau structures in Indonesia. temples, and the Hindu destinations in Java. B universal values (OUVs).

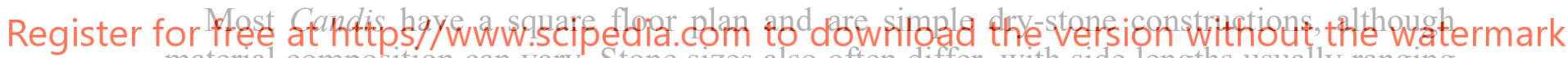
material composition can vary. Stone sizes also often differ, with side lengths usually ranging between $30 \mathrm{~cm}$ and $50 \mathrm{~cm}$. Interior spaces, where they exist, are not intended to accommodate large groups of worshippers. ${ }^{3}$ In terms of elevation, there is usually an architecturally accentuated tripartite division, consisting of a substructure which forms the basis, the wall zone, and the temple roof. The interior space is covered by a corbel vault, visible both on the inside and in the shape of a pyramid roof on the outside. Candis occur in different variations, often as a group of buildings with surrounding walls, gates and accompanying smaller temples. Their position within the landscape and their architectural design is determined by a series of sociocultural, religious, and economic factors.

\subsection{Earthquakes}

The Pacific Ring of Fire, a tectonic subduction zone, is well-known for its tendency towards environmental catastrophes such as earthquakes, volcanic eruptions and the resulting tsunamis. In Indonesia, earthquakes scoring 5 to 6 on the Richter scale are an almost daily occurrence. In the past 100 years, 175 earthquakes with a strength of at least 7 have been measured in the Indonesian area. ${ }^{4} \mathrm{~A}$ devastating earthquake of 6.2 Richter scale hit the region around 
Yogyakarta in 2006, killing almost 5,700 people and completely destroying over 156,000 houses and other structures. ${ }^{5}$ The large number of buildings destroyed reflects the high seismic vulnerability of existing structures. Several temple complexes were also damaged. There has been partial documentation of the damage to some of the more well-known temples such as Prambanan, which suffered severe damage. ${ }^{6}$

The preservation of the cultural heritage of such problematic regions is challenging and deserves a carefully-considered approach. Digital data recordings can help to virtually capture the current state of the monuments. In case of a natural disaster, this information can be consulted to assess the potential danger of collapse, or form the basis for reconstruction work.

\subsection{Monitoring workflow}

The high number of earthquakes means that especially the numerous smaller, lesser-known temples are at risk. Many of the sites have to be temporarily closed to visitors after an earthquake for safety reasons, which often results in large financial losses being incurred by many small local communities. In order to provide a simple and economical solution to enable continuous monitoring, a method for rapid, reliable and cost-effective monitoring and evaluation of the situation has been developed.

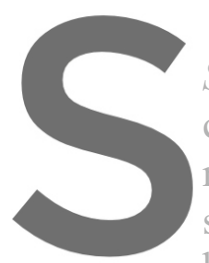

As part of a contribution to the Internationa
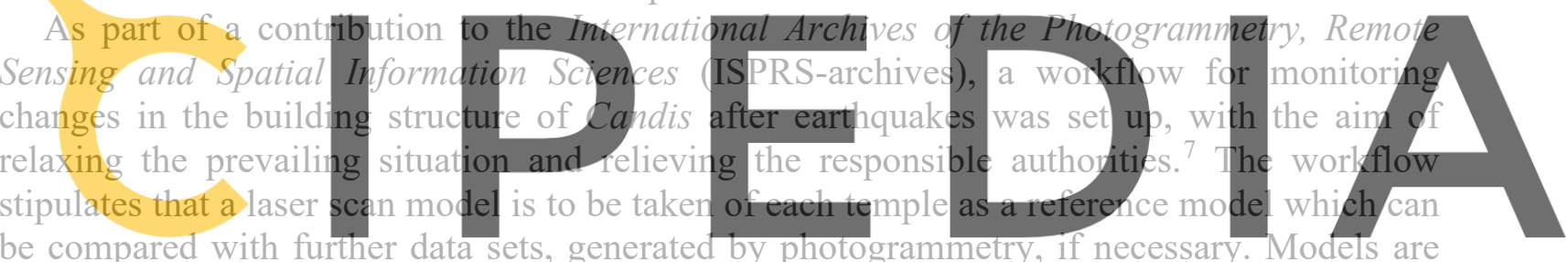

be compared with further data sets, generated by photogrammetry, if necessary. Mocels are matched using iterative closest point algorithm (ICP) and compared for cloud to cloud distance.

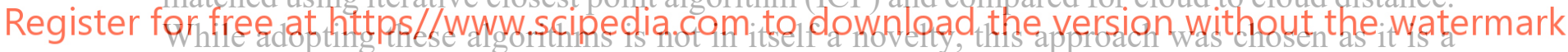

quick, simple and well-established technique which delivers sufficient accuracy. This also replaced the use of points measured using a total station, as the reliability of any physical reference on-site might no longer be guaranteed after an earthquake. Although matching datasets with cloud to cloud has its limitations, the inability to apply this algorithm properly due to clouds that are significantly different would in itself be an indicator for the necessity for more extensive investigations.

The laser scans and the preliminary work will initially be carried out as a joint effort by the Vienna University of Technology (TU Wien) and the Universitas Gadjah Mada (UGM), but as the project and knowledge transfer progresses, UGM will gradually take over the work. All further on-site applications should in any case be immediately feasible if necessary and therefore require simple explanation and handling. The implementation of local monitoring should then be within the competence of the responsible authorities in cooperation with UGM.

Whereas the above-mentioned ISPRS-contribution focused on describing operational and technical details about the workflow, the aim of this work is to elaborate steps taken to increase feasibility. 


\section{MATERIALS AND METHODS}

\subsection{Literature}

There is some literature available concerning the Candis of Java. Numerous publications and case studies have been written about the great temples like Borobudur or Prambanan. In addition, there are some diploma theses and dissertation projects concerning Candis. Many of the studies focus on religious, cultic, and cultural structures in the context of the different temples.

\subsection{Existing plans and documentation}

Except for the well-documented temple complexes such as Borobudur or Prambanan, plans for Candis are scarce. Several building surveys were commissioned by Balai Pelestarian Cagar Budaya Daerah Istimewa Yogyakarta (BPCB DIY - Cultural Heritage Conservation Centre, Special Region Yogyakarta) in the second half of the 20th century. The results show ground plans and sections which show the outlines of the objects to a relatively high degree of accuracy, but information on the construction itself is either incomplete or missing. Furthermore, no detailed plans of reconstruction work or replacement of elements are available. Occasionally,

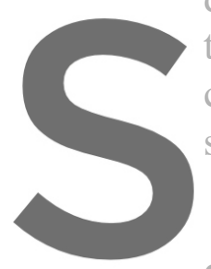
there are abstract plans construction of the tem stone construction methods to

\subsection{Case study}
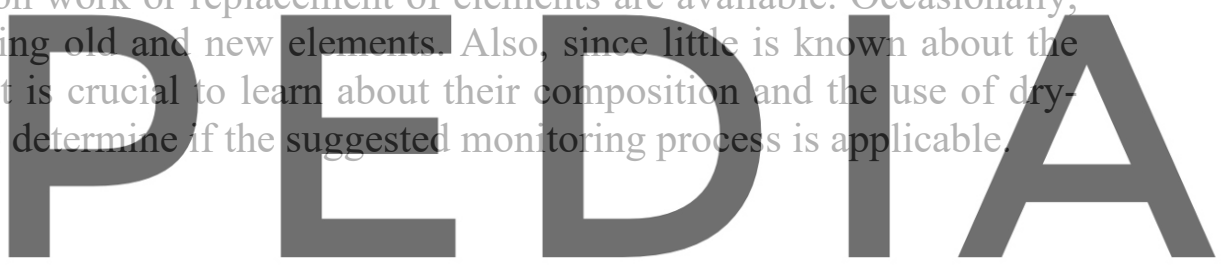

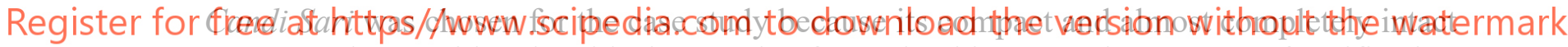
structure can be considered an ideal example of a study object. For the purpose of verification of principles, Candi Sari represents an ideal object because it is free standing and accessible from all sides. It has an interior space with multiple rooms, limited vegetation in the surrounding area, and several openings interlinking interior and exterior data through visual connection between inside and outside. Point cloud data from the case study object is available from a terrestrial laser scan (TLS) made by the authors in 2016. In 2018, this was supplemented with a structure-from-motion (SFM) point cloud processing images captured with a drone. Both data sets are presented in the ISPRS-archives contribution. To further test the data, additional point clouds were collected in the summer of 2019, one again using a TLS, and the other with a model from images taken with a hand-held camera. This should help to check the previous models for mistakes and changes, and allow a detailed study of the monitoring process within one object.

\subsection{Other Candis}

In order to develop a comprehensive monitoring system for the Special Region of Yogyakarta, the data set needs to be expanded. During a workshop in 2017, participants from 
the TU Wien and UGM worked in mixed teams on the documentation of Candis. In total, twelve temples were surveyed using a terrestrial laser scanner and photogrammetry. The number of Candis surveyed is sufficient for the first application tests but should increase further along in the project.

\subsection{Guidelines for photogrammetry}

The correct way of taking photos for SFM models requires a number of basic rules to be followed, which have been summarized in a manual proposed as part of the ISPRS paper. This should enable non-experts to take appropriate photos for processing sufficient data. The comprehensibility and practicability of the instructions should be tested on several volunteers for evaluation. The goal is to translate it into several languages to increase accessibility.

\section{RESULTS}

\subsection{Building structure and seismic resistance of Candis}

There is as yet no consistent documentation giving information about the material composition of the individual Candis and in any case, this can also differ between erection and restoration phases. Contrary to some of their counterparts in Indian stone architecture, which are carved entirely from solic rock, candis are constructed usir binding agents, with a blocks to shape the temple ${ }^{8}$
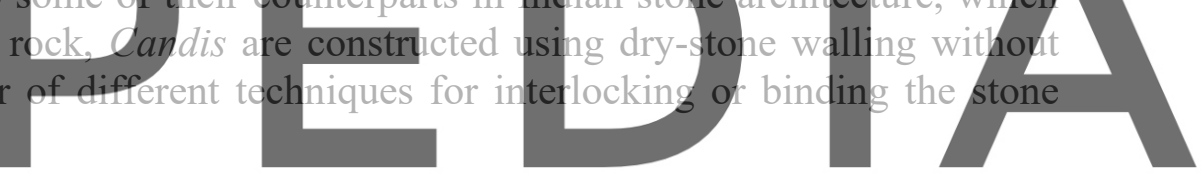

Register for free at https//www.scipedia.com to download the version without the watermark

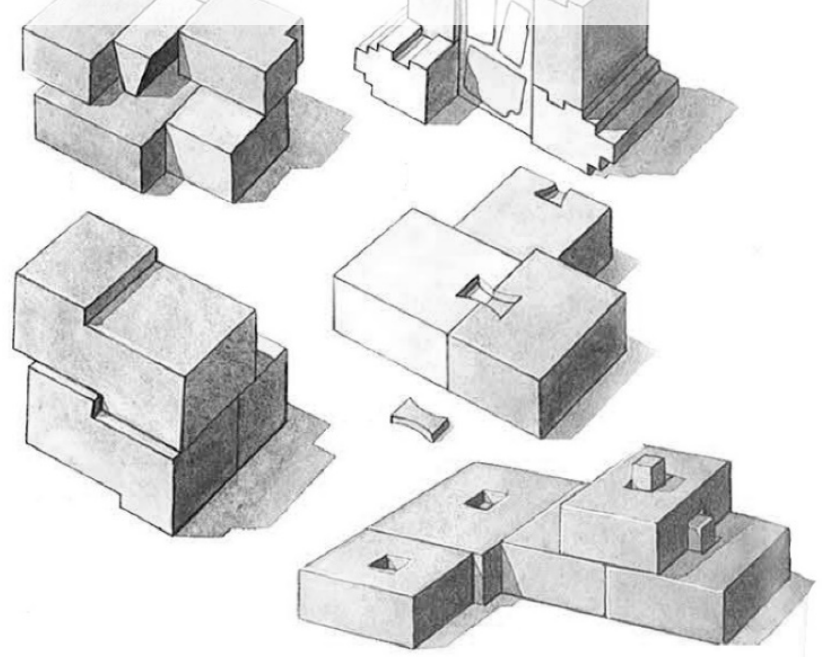

Figure 1: Different examples of interlocking stone blocks (John Miksic, 'Sources of Early Indonesian Stone Architecture', in Gunawan Tjahjono, ed., Indonesian Heritage (Singapore, 1998), p. 54.) 
Later examples show the application of a shell and core principle, with stone blocks forming wall cheeks that are filled with rubble and/or unhewn stones held together by mud or sometimes lesser amounts of lime. ${ }^{9}$ Without knowledge about a construction, it is difficult to predict how it would respond to an outside force such as an earthquake. In general, estimating seismic resistance for masonry constructions is a complex process. The inhomogeneous distribution of materials and irregular order of joints exceed the capabilities of a detailed calculation. As a result, conventional methods of determining earthquake resistance simplify the process to a great extent, thereby largely underestimating the structures' potential. ${ }^{10}$ The amount of horizontal forces (as they occur during an earthquake) that can be absorbed in a masonry wall is directly impacted by the quantity of vertical forces such as weight, creating friction within joints. Depending on these vertical forces, scenarios can include either a failure of stones or failure of joints. ${ }^{11}$ Methods to bind or interlink building elements with each other, as found in some Candis, would be advantageous, but make calculations even more complex. The undocumented extent of applying these constructional features appear to make a realistic or even acceptably simplified calculation of earthquake resistance for Candis impossible today.

In addition to the detail-specific observation of earthquake resistance, as described above, the geometry of a building has a strong impact on its behaviour during a seismic event. The ideal shape in terms of earthquake resistance would be to have a certain symmetry of shape. This criterion can be achieved by a structure having as many axes of symmetry ideally an infinite numb floor plan and a compact times the length of the so (E.g.: Candi Banyunibo compact and symmetrical shape, a large, almo
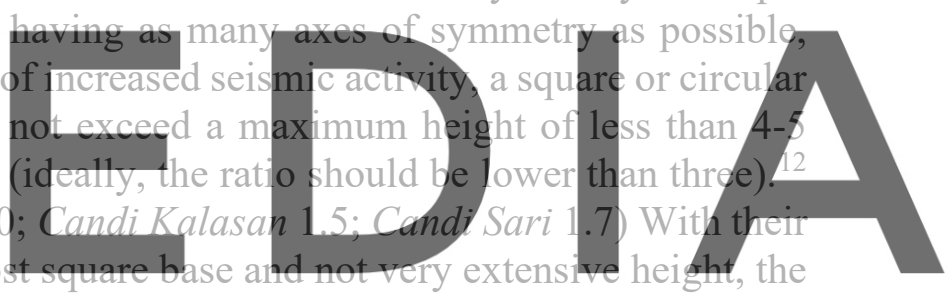
general appearance of Javanese Candis appears positive in terms of earthquake resistance.

Register for free at https//www.scipedia.com to download the version without the watermark

\subsection{Reference model}

As part of the contribution to the ISPRS-archives, as mentioned in the introduction, the process for acquiring a reference model for monitoring structural changes through seismic events was introduced. A base model with extensive coverage of the surfaces was collated for the case study object Candi Sari: this consists of a dataset of TLS point clouds supplemented by image-matching data from drone photography.

The results presented in the above-mentioned ISPRS paper allow an informed judgement regarding the usability of collected data as reference for a monitoring program for Javanese Candis. As shown within the analysis, the use of a combined laser scanning and UAV supported image-matching model should deliver proper accuracy and coverage which can be used as a reference model. The paper also presented the use of iterative closest point algorithm matching as a valuable tool for data combining, even in the absence of the possibility of measuring fixed target points that appear in both laser scanning and image matching data. Applying this workflow, a point cloud density with 50 to 70 neighbours within a range of $0.02 \mathrm{~m}$ around a point in most areas, a suitable representation of the as-is state of the object was suggested. 


\subsection{Control models}

As a second element to monitoring changes in Javanese Candis, procedures were discussed that would allow investigations to be conducted within a relatively short time-frame. These included the proposal to introduce and familiarize local temple staff and guards to the workflow and provide them with the necessary guidelines for effectively taking images that can be further processed into a 3D point cloud, using SFM. Observations from Candi Sari show that the quality of the images and choice of angles are essential to be able to achieve sufficient accuracy in the control model, to allow an assessment of the current state of the monument.

To determine the required quality for a model, several campaigns focused on the same case study object. As a result, the initial reference model, which used TLS from 2016 and UAVsupported SFM covering the roof structures from 2018, was supplemented by an SFM-model from a student workshop in 2017. In addition to the data presented in the ISPRS contribution, it was possible to include Candi Sari in another campaign in the area in 2019, thus delivering a second TLS-model and a high accuracy SFM-model.

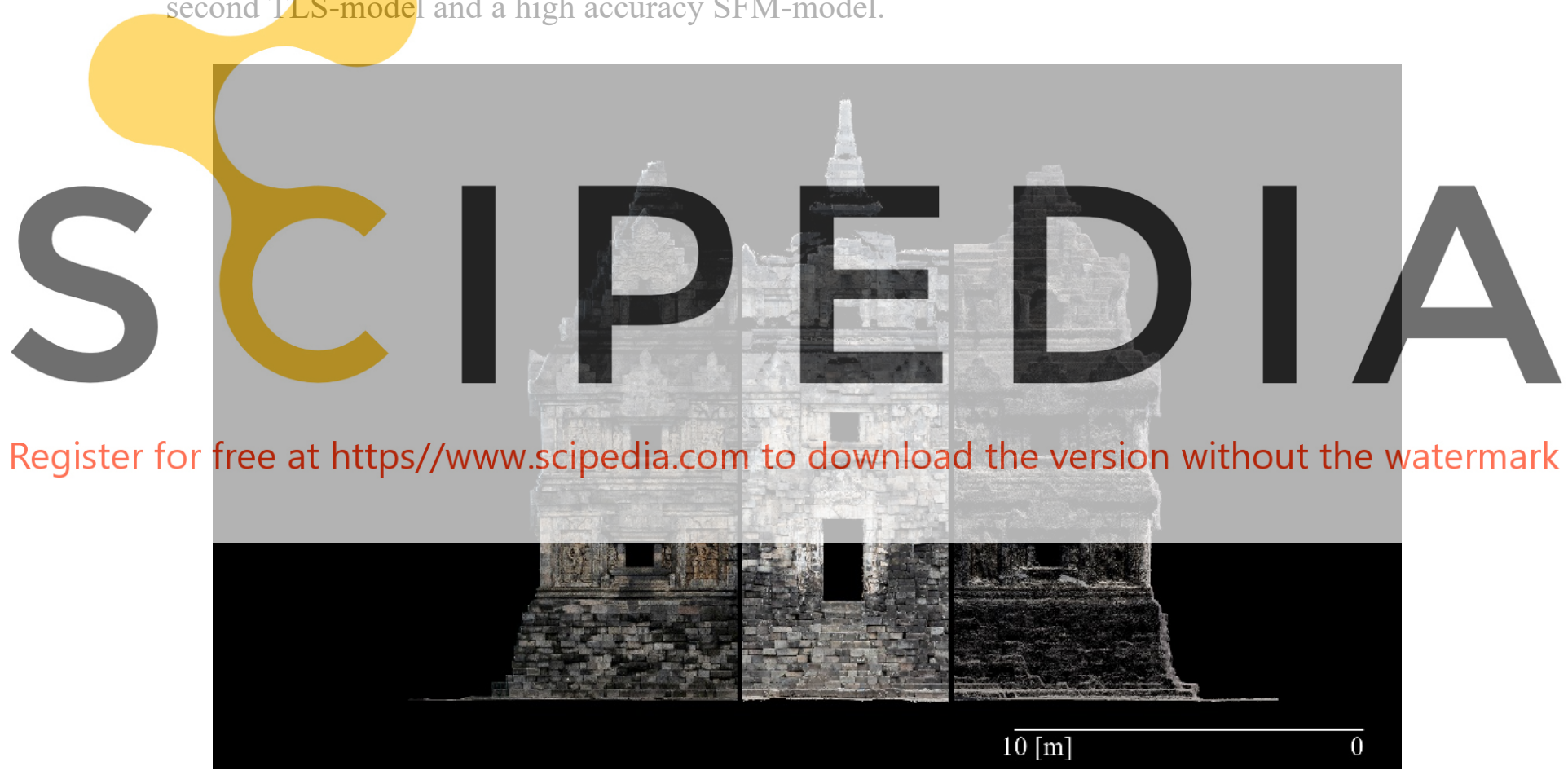

Figure 2: Point clouds from terrestrial laser scan, image-matching and drone image-matching

Using this data, we can now not only see the capabilities and limitations of image-matching for monitoring purposes, but also test for any shortcomings in the laser scanning process. Further, given that time has passed between capturing the different models, numerous earthquakes have impacted the structure.. This should allow the visualization of any changes that might have occurred by comparing two laser scanning models and check if image-matching would deliver sufficient information to pinpoint such changes. 


\subsection{Shifts and changes}

A comparison of the 2016 TLS model and the 2019 SFM model showed some minor changes within the structure. Furthermore, using the 2019 TLS model, it was clear that these changes were not the result of shortcomings in the image-taking or image-matching process leading to the control model, but rather are actual structural changes in the monument. Although these are not considered to be the result of any seismic activity, but of human interaction with the object, they are at this point still seen as exemplary in determining the scale on which shifts within the structure could be discovered using the techniques proposed.

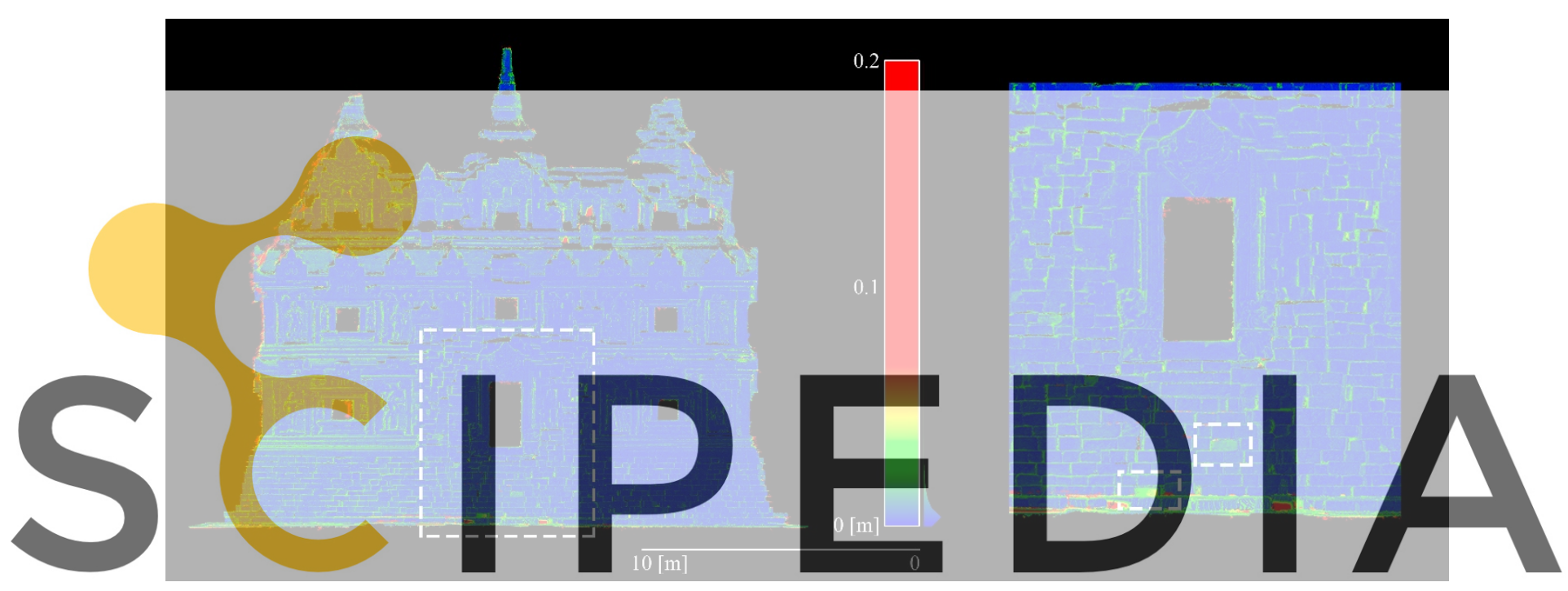

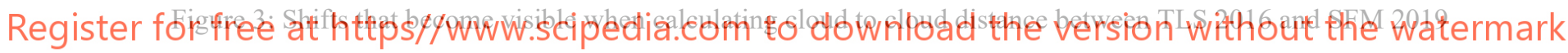

The first of the shifts is rather extensive and easy to spot, as it is one loose stone block in the entrance area that has undergone some rotation on the ground (Fig. 3 \& Fig. 4, lower left). The second movement that could be observed from comparing the 2019 SFM model with the 2016 TLS model was much smaller, but still visible in the false-colour elevation showing the cloud to cloud distances between the two point cloud data sets (Fig. 3 \& Fig. 4, top right). Observing the same block in a horizontal section, the extent of the movement becomes apparent. In this case, the stone has moved about two centimetres and allows a rough estimation of what changes could be recognized using the proposed technique. Again, a comparison of the old and the new TLS dataset was used to prove that the observed shift was not the result of a procedural inaccuracy, but an actual movement of one element in the structural composition. 

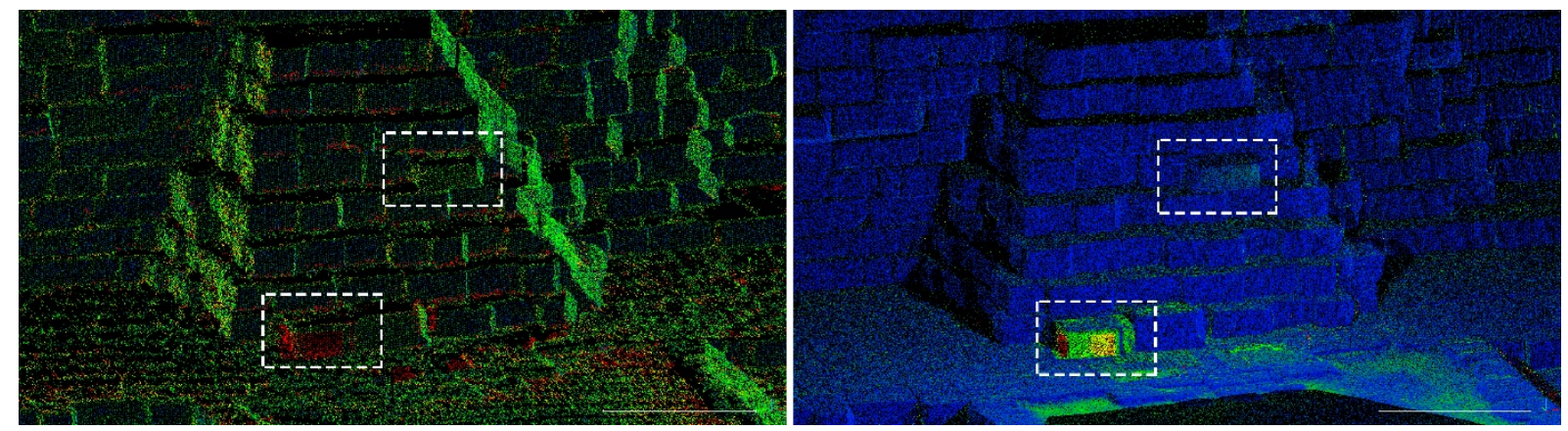

Figure 4: Three-dimensional point cloud representations of shifts and changes - SFM 2019 and TLS 2016 (left); TLS 2019 and TLS 2016 (right)

\subsection{Data from student workshop}

Data collected during the above-mentioned student workshop was further analysed to determine a specific workflow and key factors during post-processing that could facilitate the generation of digital models of Candis. In order to comply with the proposed methodology, reference models using drone SFM and TLS were connected using targets (measured points for connecting different data sets), while procedures investigated for application in collating control models had to $r$ were analysed, the photogrammetric UAV and TLS data for re determine the centre, and thus this form of $p$ examples, the reflectors were ignored after all
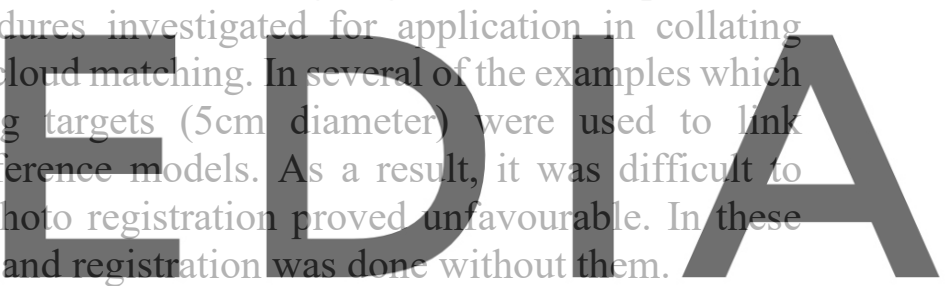

In some of the examples analysed, drone photography was performed using only ground

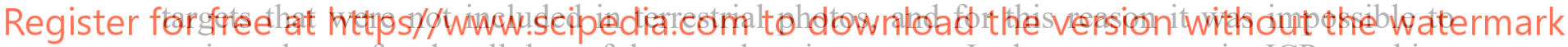
register the roof and wall data of the temple using targets. In these cases, again, ICP matching needed to be applied. Some examples even failed cloud to cloud matching, as TLS point cloud density was insufficient in overlapping areas (e.g., Candi Ijo).

The photogrammetric connection between indoor and outdoor areas proved to be particularly difficult during capturing control models. In some cases, it was not possible to accurately merge the parts into one model. To avoid this situation, it would be necessary to position a minimum of four targets that are visible from both perspectives. Since the proposed workflow does not include the measuring of points, but focuses solely on the use of SFM, an alternative needs to be sought. While it would be possible to use ICP matching to link interior and exterior areas to the reference model separately, this could prove a disadvantage for recognizing structural changes. Further problems occurring during photogrammetric capturing included an insufficient number of pictures, the mixture of landscape- and portrait format or different cameras, as well as pictures taken in unfavourable lighting conditions (e.g., at sunset).

While the insufficient data quality of some Candis led to difficulties during post-processing, data from other Candis proved that by using adequate capturing procedures, the suggested workflows can successfully generate the expected results. With Candi Banyunibo, all point clouds were successfully matched, and the required plan data was generated. 


\section{6 "Easy handle manual"}

As was demonstrated, the usability of images for creating SFM models depends largely on the quality of the pictures as well as the proper choice of angles from which those images are taken. Therefore, it was clear that instructions for the capturing process needed to be developed. A so-called "Easy handle manual" was drafted to graphically explain the process. Based on existing work as promoted by the International Committee for Documentation of Cultural Heritage (CIPA), ${ }^{13}$ instructions given for common SFM software, and personal experience, the manual is intended to introduce the procedure to non-experts step by step. To overcome cultural and language barriers, the manual provides illustrations for each of these steps and was made available in German, English and Indonesian.

Originally, the aim was to test this manual on volunteers, and to present the results as part of this paper. Unfortunately, this was not possible due to environmental conditions on site.

\section{DISCUSSION}

\subsection{Surface comparison for monitoring}

Calculation methods alone seem to be insufficient to provide an adequate representation of

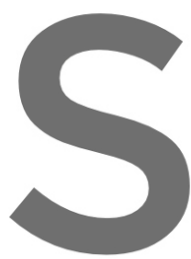

the flow of forces throu used to assemble a Can monument. Therefore, as the different means o blocks are too complex.
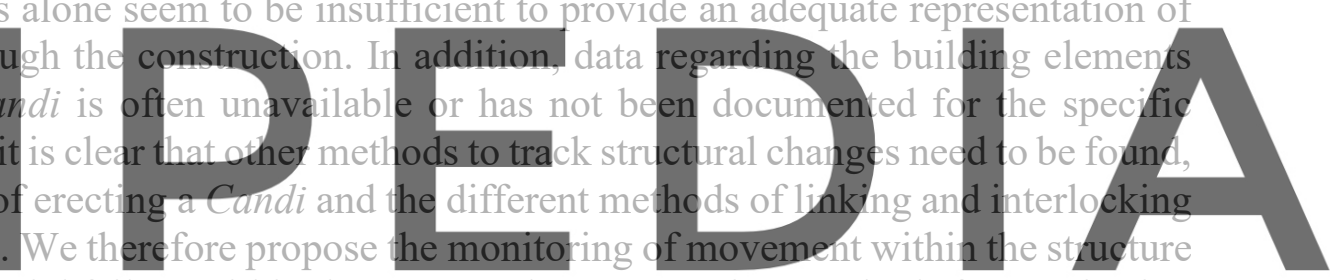

and observation of material failure within the stonework as appropriate methods for monitoring

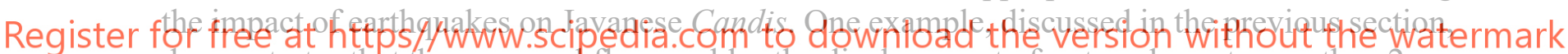
demonstrates that the new workflow enables the displacement of a stone by not more than $2 \mathrm{~cm}$

to be recorded (compared to a SFM-based control model with a TLS reference model (Figure

$3 \&$ Figure 4)). The question is whether this is sufficient to assess the structural stability of a Candi after a seismic event. It is believed that, given the common constructional techniques (despite variations) and average size of building elements, the workflow would prove to be a valuable tool for a preliminary assessment.

\subsection{Limitations}

Although, as mentioned, models from images taken in ideal conditions have shown good capabilities for capturing structural shifts, they are still largely dependent on two factors, one being the ability and level of skill of the person acquiring the images. Despite providing a manual, or even instructing on-site personnel on how to collect such images in case this is necessary, it is uncertain whether the resulting data will be usable. Therefore, this component of the proposed workflow should be the one given the greatest attention during the next steps of the project - as is currently the case. Image-quality remains a factor difficult to control, as it is uncertain what kind of devices might be available at the time an assessment is needed. 
Another area that remains under-investigated in this work in its current state is the monitoring of interior spaces in Candis. Since most of them are small, with few or no windows or artificial light sources, the possibilities to use photogrammetry for monitoring the interior spaces certainly needs closer investigation and maybe even amendment of the monitoring procedure.

\section{CONCLUSION}

Although the proposed monitoring workflow is in theory already fit for purpose, there are still steps to be taken to assure the quality of assessment and enable correct implementation. Primarily, the process of capturing control models needs to be explored further and the manual critically tested and amended to ensure photogrammetric data can be captured as and when needed. Moreover, a more extensive network of reference models for Candis must be built up. A priority list should be compiled according to the policy and judgement of those in charge. It is the intention of the authors of this paper to provide and improve the workflow, as necessary, but not to be the monitoring instance. Therefore, it is crucial to explore how the local authorities (who are already involved) can best take over the main tasks of continuously capturing and managing reference models, with the TU Wien taking a step back and limiting itself to a supporting and advising role.

All investigations done so far to challenge the applicability of the proposed workflow indicate that a usage for tracing changes in Javanese Candis should be possible. We aim to continue and expand our research until we can provide a comprehensive workflow that reliably helps to monitor the state of Javanese Candis and allows a rapid assessment of these economic drivers when they have been impacted by seismic events. 


\section{REFERENCES}

[1] Risda Asfina and Ririn Ovilia, 'Be proud of Indonesian cultural heritage richness and be alert of its preservation efforts in the global world', Humanus, 15 (February 2017), p. 198. [2] John Miksic, 'Sources of Early Indonesian Stone Architecture', in Gunawan Tjahjono, ed., Indonesian Heritage (Singapore, 1998), p. 54.

[3] John Miksic, 'Sources of Early Indonesian Stone Architecture', in Gunawan Tjahjono, ed., Indonesian Heritag (Singapore, 1998), p. 54.

[4] U.S. Geological Survey, 'USGS Earthquake Hazards Program', USGS Earthquake Hazards Program (January 2020),

[5] Amr S. Elnashai, 'The Yogyakarta earthquake of May 27, 2006' (2007), p. 7.

[6] Amr S. Elnashai, 'The Yogyakarta earthquake of May 27, 2006' (2007), p. 42.

[7] U. Herbig, L. Stampfer, D. Grandits, I. Mayer, M. Pöchtrager, Ikaputra, and A. Setyastuti, 'Developing a monitoring workflow for the temples of Java', Int. Arch. Photogramm. Remote Sens. Spatial Inf. Sci., XLII-2/W15 (August 2019), pp. 555-562.

[8] Jacques Dumarcay, 'Buddhist Architecture of Central Java', in Gunawan Tjahjono, ed., Indonesian Heritage (Singapore, 1998), p. 56.

[9] Jacques Dumarcay, 'Indonesian Methods of building with stone', in Gunawan Tjahjono, ed., Indonesian Heritage (Singapore, 1998), p. 57.

[10] Konstantin Meskouris, ed., Bauwerke und Erdbeben: Grundlagen - Anwendung Beispiele (Wiesbaden, 2011), p. 469.

[11] Meskouris, ed., Bauwerke und Erdbeben, p. 470.

[12] Adrian Pocanschi, Kräfte in Bewegung : die Techniken des erdbebensicheren Bauens (2013), p. $344 \mathrm{f}$.

[13] P. Waldhäusl, C. Ogleby, J.L. Lerma, and A. Georgopoulos, ' 3 x 3 rules for simple photogrammetric documentation of architecture' (2013); P. Waldhäusl and C. Ogleby, ‘3 x 3

rules for simple photogrammetric documentation of architecture', ISPRS - International Archives of Photogrammetry and Remote Sensing, 30 (1994), pp. 426-429; Peter Waldhaeusl, 'Photogrammetric Heritage Recording: Standard and Emergency Approaches', APT Bulletin, 26 (1994), p. 20. 